\title{
Reported Māori consumer experiences of health systems and programs in qualitative research: a systematic review with meta- synthesis
}

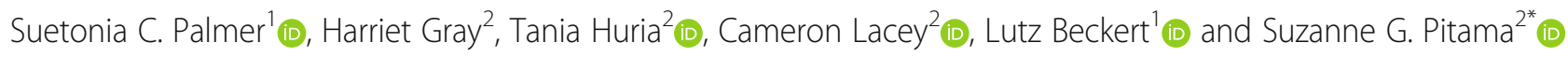

\begin{abstract}
Background: Persistent inequities in health experiences and outcomes are observed for Māori compared to nonMāori in Aotearoa New Zealand. We conceptualised factors associated with Māori consumer experiences of health programs and services and characterise how the recommendations arising from qualitative research inform strategies to address inequities.

Methods: In this systematic review, electronic literature searching was conducted in February 2018. Qualitative studies reporting Māori consumer experiences of health services and programs in Aotearoa New Zealand were eligible. Māori consumer experiences of health services were mapped to the WHO Commission of Social Determinants of Health (CSDH) conceptual framework on health inequities as related to: (i) the socioeconomic and political context; (ii) socioeconomic positioning; or (iii) intermediary factors that increase exposure to health-compromising conditions. Recommendations to improve consumer experiences were mapped to the CSDH framework for tackling social determinants of health inequities as policy directions on: (i) unequal consequences of illness (individual interaction); (ii) risks of exposure to health-damaging factors (community); (iii) exposures to health-damaging factors (public policies); and (iv) mitigating effects of socioeconomic and political stratification (environment).
\end{abstract}

Results: Fifty-four studies were included. Māori consumer experiences mapped to social determinants of health inequities were most frequently related to direct interactions with health services and programs, particularly patient-clinician interactions (communication, relationships) and cultural competencies of clinicians and the system. Key recommendations by researchers mapped to potential strategies to address inequity were identified at all levels of the political, social and health system from individual interactions, community change, and broader public and system-level strategies. Recommendations were predominantly focused on actions to reduce risks of exposure to health-damaging factors including health literacy interventions, increased resources in cultural competencies and Māori capacity in health service development and workforce.

Conclusions: Mãori consumer experiences of health services and programs are an important informer of variables that impact health inequity. Strategies to tackle health inequities informed by Māori consumer experiences can be drawn from existing empirical research. Future qualitative exploration of how socioeconomic, political and public policies influence Māori consumer experiences of health services and programs could inform a broader range of structural policies to address health inequities.

Keywords: Indigenous, Health services, Quality, Synthesis, Systematic review

\footnotetext{
* Correspondence: suzanne.pitama@otago.ac.nz

${ }^{2}$ Māori and Indigenous Health Institute, University of Otago Christchurch, 45

Cambridge Terrace, Christchurch 8140, New Zealand

Full list of author information is available at the end of the article
}

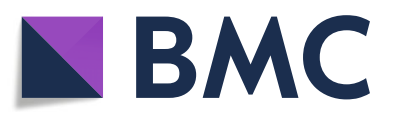

(c) The Author(s). 2019 Open Access This article is distributed under the terms of the Creative Commons Attribution 4.0 International License (http://creativecommons.org/licenses/by/4.0/), which permits unrestricted use, distribution, and reproduction in any medium, provided you give appropriate credit to the original author(s) and the source, provide a link to the Creative Commons license, and indicate if changes were made. The Creative Commons Public Domain Dedication waiver (http://creativecommons.org/publicdomain/zero/1.0/) applies to the data made available in this article, unless otherwise stated. 


\section{Background}

Persistent and marked inequity is observed for Māori at all levels of health, [1] education (Ministry of Health, Ministry of Education: Māori participation and attainment in science subjects, unpublished) and justice [2] in Aotearoa New Zealand. Non-Māori have life expectancies approximately 7 years longer than Mãori, attain higher educational achievement in secondary and tertiary education, and are incarcerated at markedly lower levels. In primary and secondary health care, non-Māori patients are prescribed more effective medications [3], are referred more often to specialist services [4] and experience higher quality hospital care [5]. Non-Māori patients experience persistently lower rates of preventable diseases that lead to avoidable hospitalisation and unmet need in primary care [6]. Māori experience inequitable access to health services throughout the life course leading to higher rates of disability and multiple morbidity [7]. Māori are more likely than non-Māori to cite cost as a barrier to accessing primary care. In addition, nationwide quality improvement programs in Aotearoa New Zealand worsen inequity by differentially improving access to services for non-Māori [8-10].

Patient-centred research can facilitate the understanding of consumer experiences, perceptions and expectations of health services to generate insights and knowledge that guide improvements in healthcare acceptability and quality [11]. In the last two decades, there has been an increase in qualitative research to explore patient viewpoints to inform public policy and align health service development with consumer preferences and expectations [12]. Despite this shift toward greater inclusion of patient voices in clinical health research, including with Māori consumers, health outcomes remain inequitable across numerous clinical settings in Aotearoa New Zealand and for indigenous and tribal peoples worldwide [13]. In addition to seeking patient perspectives, qualitative studies can offer critical insights into the ways that researchers view and conceptualise the patient experience and how those experiences are problematised as a basis for interventions to improve health outcomes $[14,15]$.

This study aimed to explore how Mãori consumer experiences of health services and programs in Aotearoa New Zealand are conceptualised within qualitative research, to characterise how recommended strategies to improve Māori consumer experiences can inform policy directions to address health inequities and to identify gaps in the existing evidence base.

\section{Methods}

We did a systematic review and evidence synthesis of qualitative studies reporting Māori consumer experiences of health services and programs in Aotearoa New Zealand. We used the theoretical framework of the World Health Organization (WHO) Commission of
Social Determinants in Health (CSDH) to categorise the factors reported to be associated with Māori consumer experiences of health and to evaluate how recommended strategies arising from the findings might inform strategies to address health inequities [16]. The Enhancing Transparency in Reporting the Synthesis of Qualitative Research (ENTREQ) framework was followed for this study [17].

\section{Literature searching}

Electronic searches were conducted in AMED, CINAHL, EMBASE, MEDLINE, Google Scholar, PROQUEST, and PsycINFO for qualitative studies reporting Māori consumer experiences of health services and programs in Aotearoa New Zealand from each database inception up to week 2, February 2018. We used search terms using keywords relating to Māori (Māori, First nation, Oceanic ancestry, Native), and qualitative research (Content analysis, Descriptive, Discourse, Exploratory, Grounded theory, Interpretive, Interview, Mixed method, Multi method, Narrative, Phenomenology, Qualitative, Thematic, Theme) and experiences (Attitude, Belief, Experience, Perception, Perspective, Satisfaction, Value, View). Studies that included Māori participants but that did not provide separate data analysis for Māori and non-Māori participants were not eligible.

\section{Data extraction and quality assessment}

The following basic characteristics were extracted from each study: publication year, methods for ethnicity determination, number of Māori participants, gender, cohort characteristics, health setting, topic, study methodological framework, whether kaupapa Māori methodologies were used and funding source(s). The text of each paper including tables and figures was reviewed in full text by at least two of three authors (SCP, HG, SP) to extract the following from each study: stated purpose of research, determinants of Māori participant experiences, and research responses and recommendations arising from the findings. Two authors independently assessed the transparency of reporting using the Consolidated Criteria for Reporting Qualitative Research (COREQ), which assessed study methodological reporting of the research team, methodologies, context, analysis, and interpretation [18].

\section{Data coding and analysis}

The extracted data underwent two cycles of coding by at least two of three authors (SCP, HG, SP). These authors (SCP and SP) have expertise in Māori health research or (HG) are training in Māori health research. Three authors who provided intellectual feedback on the coding also have expertise in Mãori health research (TH, CL, LB).

In the first coding cycle, descriptive coding was used to identify the basic topic for each passage of reported data in the results and discussion section of each included 
study [19]. In the second cycle of coding, the determinants of Māori consumer experiences of the health system (services and programs) were mapped against the World Health Organization Commission for Social Determinants of Health (CSDH) conceptual framework of the determinants, processes and pathways that generate health inequities [16]. The CSDH conceptual framework includes the socioeconomic and political context in which people live (governance, macroeconomic policies, social and public policies and culture and societal values), the socioeconomic positioning of people (social class, gender, racism, education, occupation and income) and the intermediary factors (material circumstances, behaviours and psychosocial factors) which, mediated through health services and programs, determine inequity in health and wellbeing. The actions recommended by researchers arising from the determinants of Māori consumer experiences were mapped against the CSDH framework for strategies tackling social determinants of health inequities. This framework describes a hierarchy of dimensions and directions for: 1) policies to reduce unequal consequences of illness in social, economic and health terms (individual interactions); 2) policies to reduce risk of exposure of disadvantaged people to health-damaging factors (community); 3 ) policies to reduce exposures of disadvantaged people to health-damaging factors (public policies); and 4) policies on stratification to reduce inequalities and mitigate effects of stratification (environment).

\section{Results}

Electronic searching yielded 4182 citations of which 293 were examined in full text (Fig. 1). Fifty-four qualitative studies were included [12, 20-72]. The comprehensiveness of study reporting is shown in Additional file 1 and in the Additional file 2. Studies reported between 4 and 26 of the 32 Consolidated Criteria for Reporting Qualitative health Research (COREQ) criteria.

Māori consumer experiences were reported within a range of health settings and programs including primary care, public health and screening initiatives, community health programs, disability and hospice services and hospital-based care (Table 1). The number of Māori participants in each study ranged between 4 and 130 . Twenty-eight studies reported funding from government sources. Eleven studies reported kaupapa Māori (Māoriled) methodologies $[12,24,35,39,56,59,61,65-67,70]$. In 24 studies, ethnicity was reported as self-identified by participants $[26,27,31,34,35,37,40,45,47-50,55,57$, $59,61,63,65-70,72]$. In two studies, ethnicity was identified through name or records, $[29,56]$.

Most (38 studies) studies aimed to evaluate consumer experiences and perceptions of healthcare and health service delivery. Fewer studies evaluated patient experiences as they related to healthcare implementation and policy (8 studies), $[46,52-54,56,67,68,70]$ cultural appropriateness of healthcare (6 studies) $[39,43,47,50,66,69]$ or to identify the causes and impact of health inequality (1 study) [36].

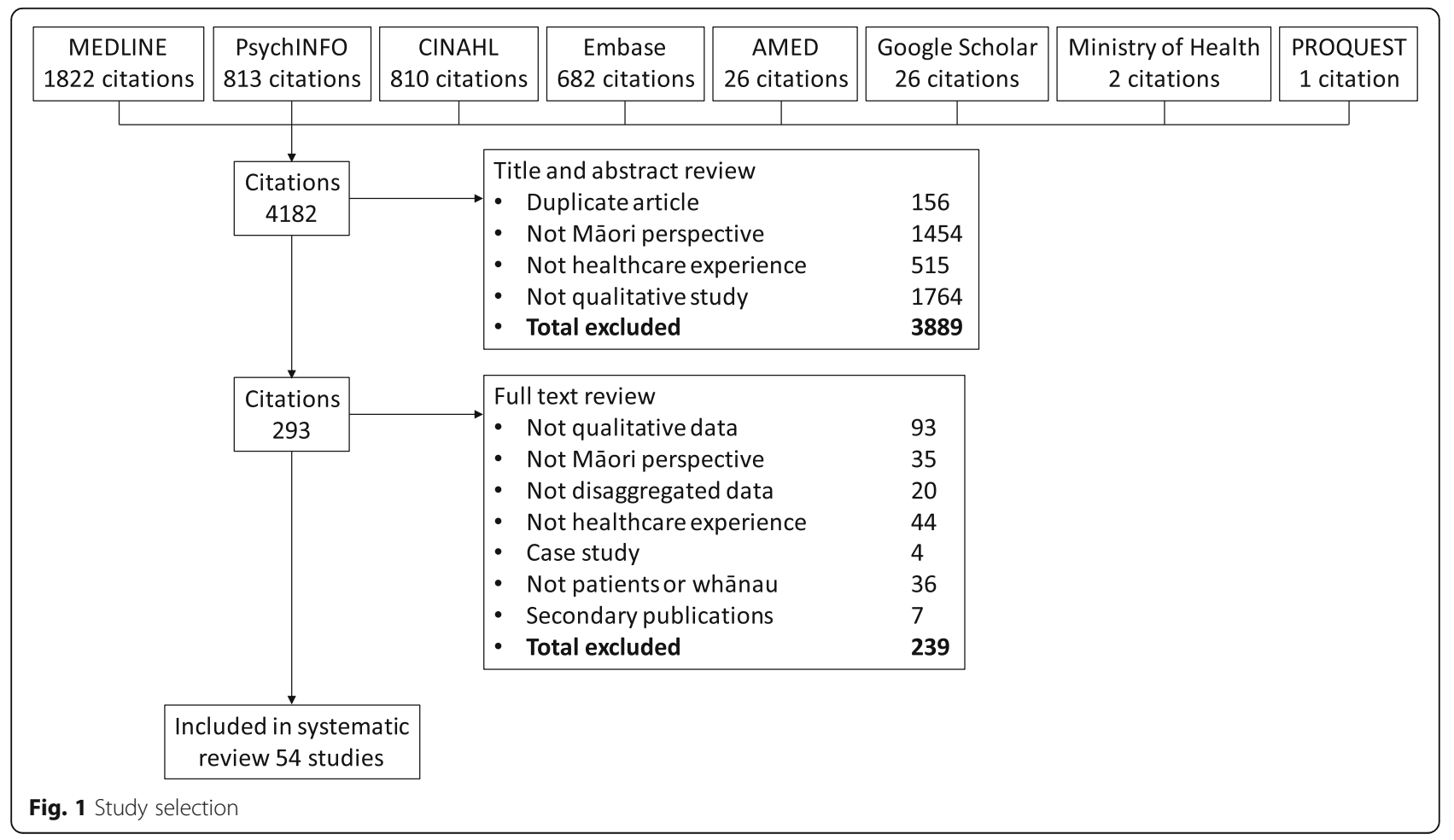




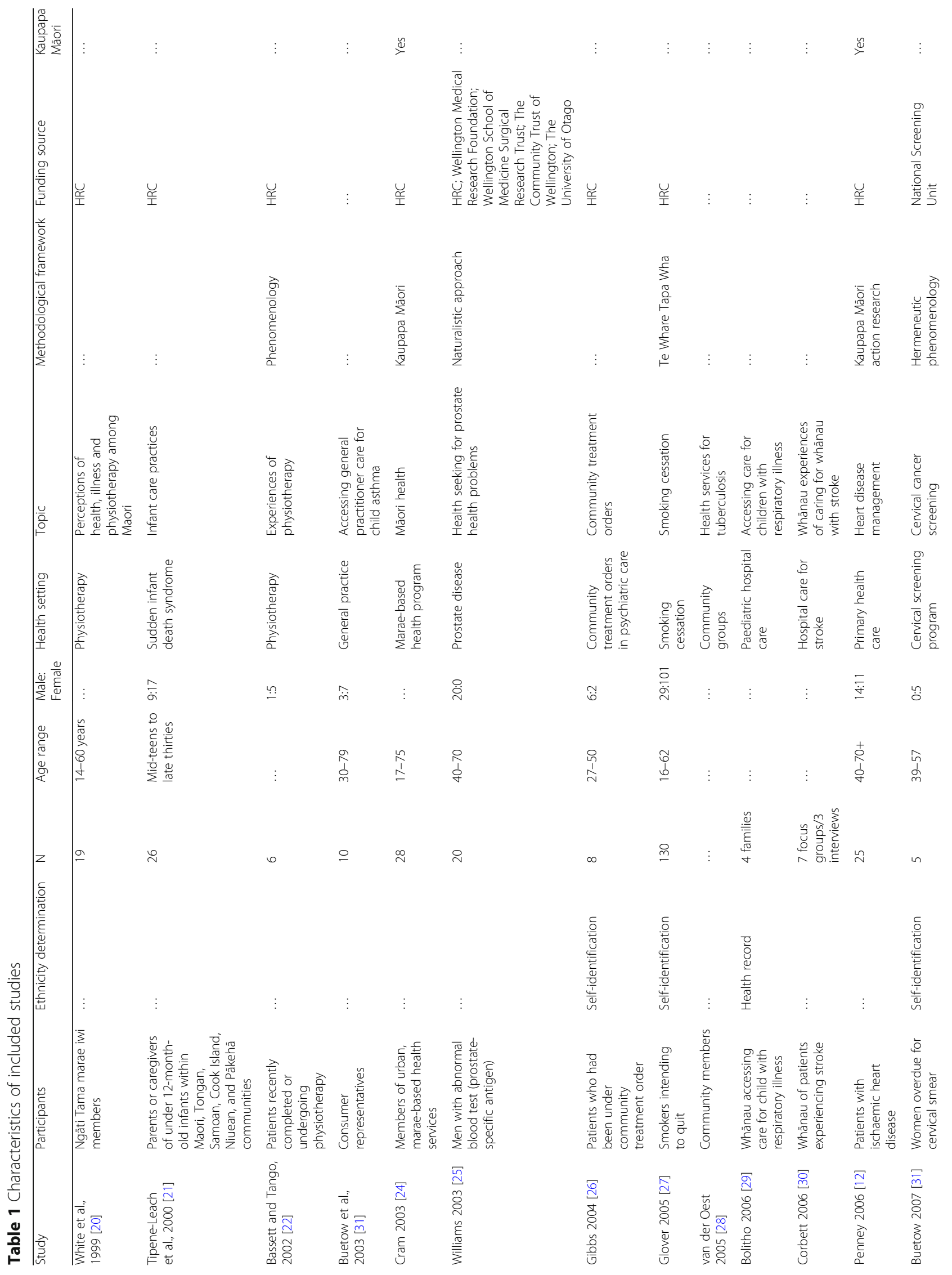




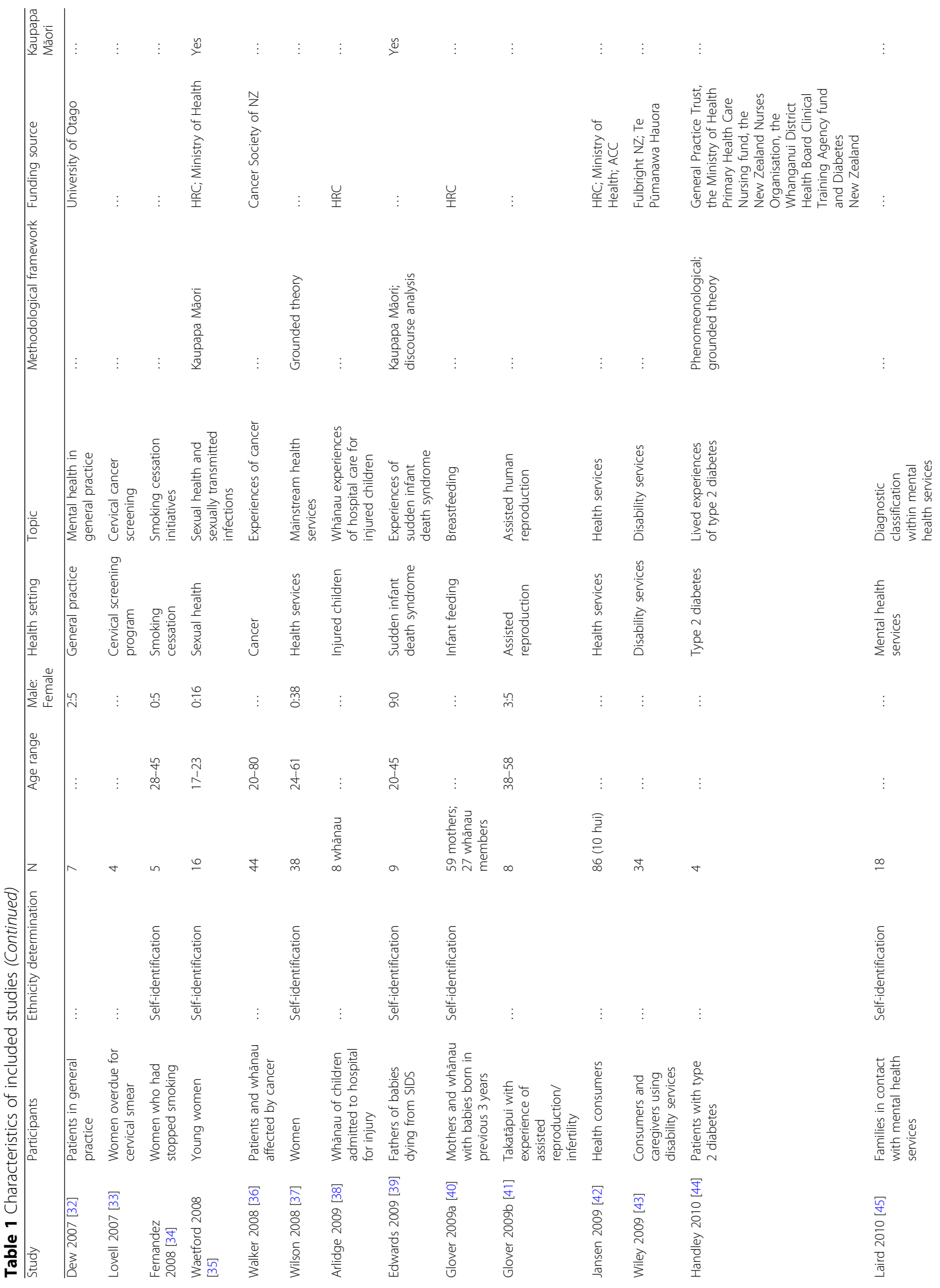




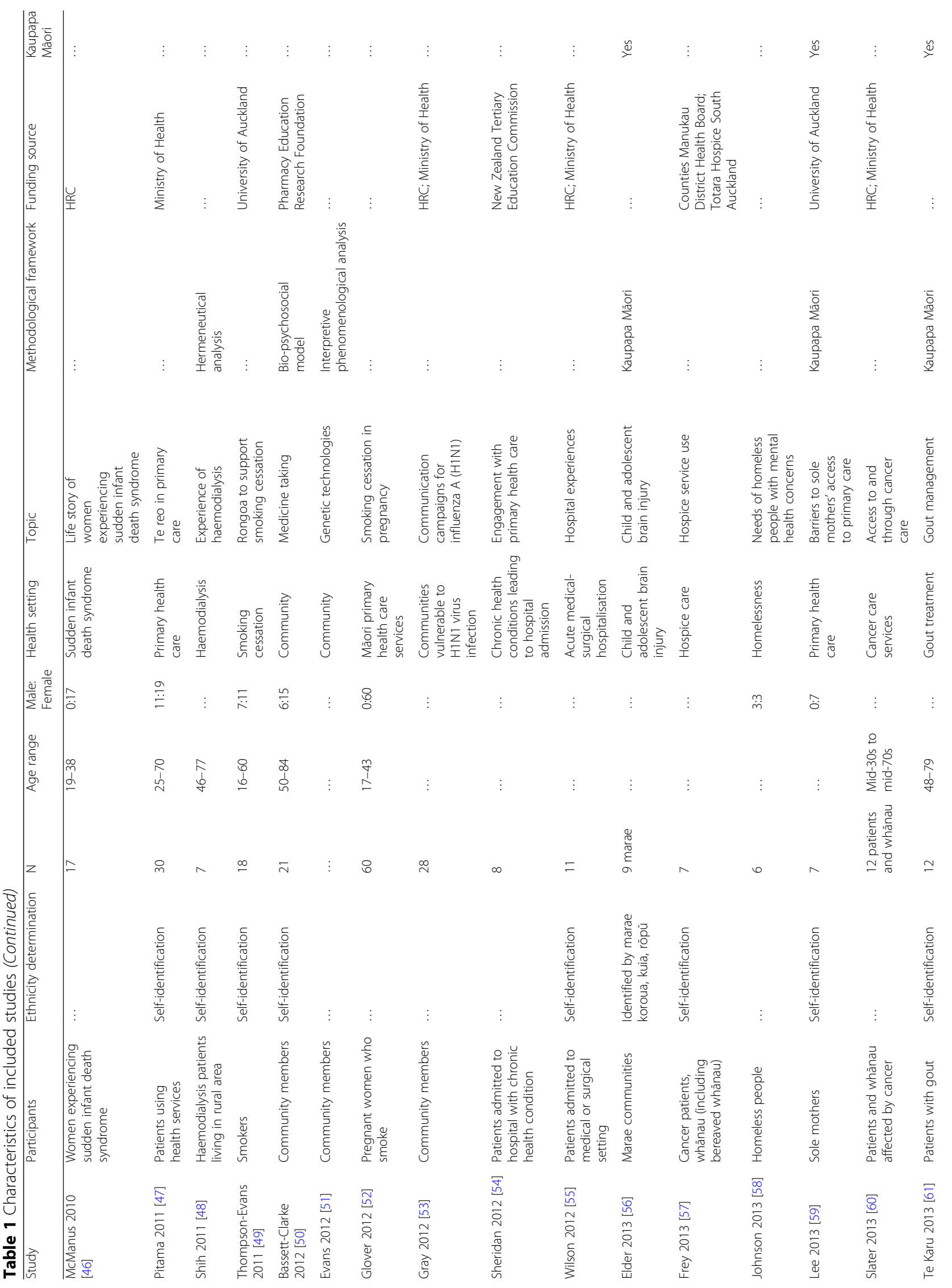




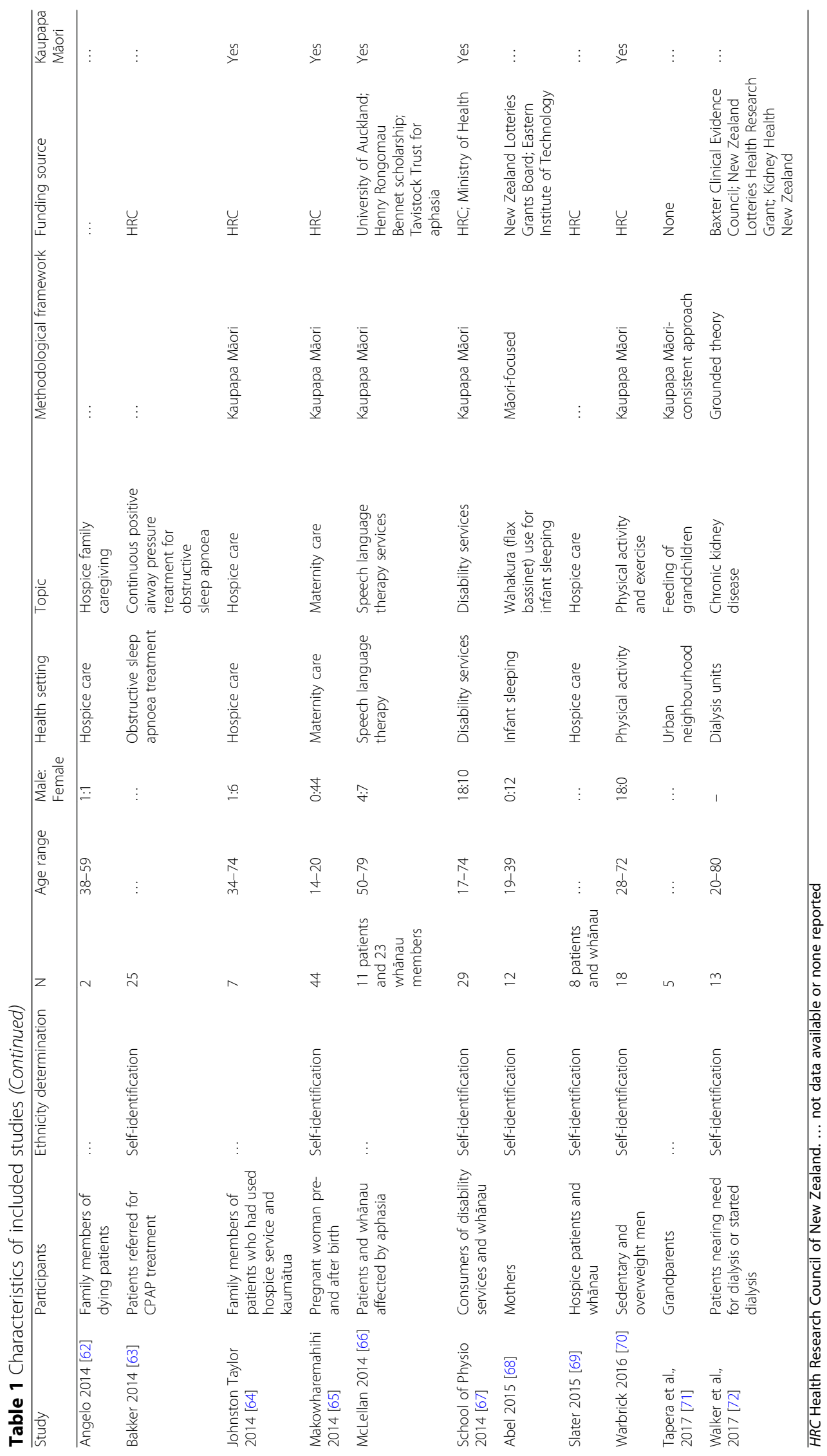


Māori consumer experiences of health that were mapped to social determinants of health inequity were most frequently identified as direct interactions with the health system (Fig. 2). These included patient-clinician communication and relationships, clinician cultural competency, tikanga (cultural mores) in health services, the physical clinical environment, whānau (extended family) involvement in care, patient support, clinical respect for patient and clinician availability. Reported Māori consumer experiences mapped to intermediary factors that lead to differential exposures to healthdamaging factors included health beliefs, cultural (dis) connectedness, costs of clinical care and internalised blame. Māori consumer experiences in the available studies were less commonly mapped to socioeconomic positioning (previous health experiences, clinician ethnicity, racism, health literacy and socioeconomic factors) and the socioeconomic or political context (public health promotion and colonisation).

Based on Māori consumer experiences, the most frequently recommended actions to improve Māori experiences of healthcare were aligned with reducing risk of exposure to health-damaging factors (such as integration of tikanga (cultural mores) in health services, health literacy interventions, increasing Māori workforce capacity and involvement in health service development, resources for cultural competency, accessibility of health services and clinician responsiveness to Māori consumers) (Fig. 3). Recommended actions to reduce the unequal consequences of illness in social, economic and health terms included culturally relevant interventions, support for whānau (extended family)-based care and involvement in the health system, holistic models of care and reflexive clinical practices. Strategies aimed at reducing exposures to health damaging factors included improved referral practices, reducing clinician bias, increased awareness of health determinants and provision of cultural competency frameworks and strategy. Proposed strategies aligned with mitigating the effects of socioeconomic and political stratification included funding of health services including increasing specialist services, socioeconomic policy actions and preventative health care and programs. Researchers also suggested mechanisms to monitor and follow-up on health equity based on Mãori consumer experiences. These included data collection processes, information sharing and empirical health research (Fig. 3).

\section{Discussion}

This paper summarises the determinants of Māori consumer experiences in health services and programs reported in qualitative studies and the actions recommended by researchers based on their findings. The findings have been mapped to the CSDH frameworks of health inequities to synthesise a range of potential strategies that might

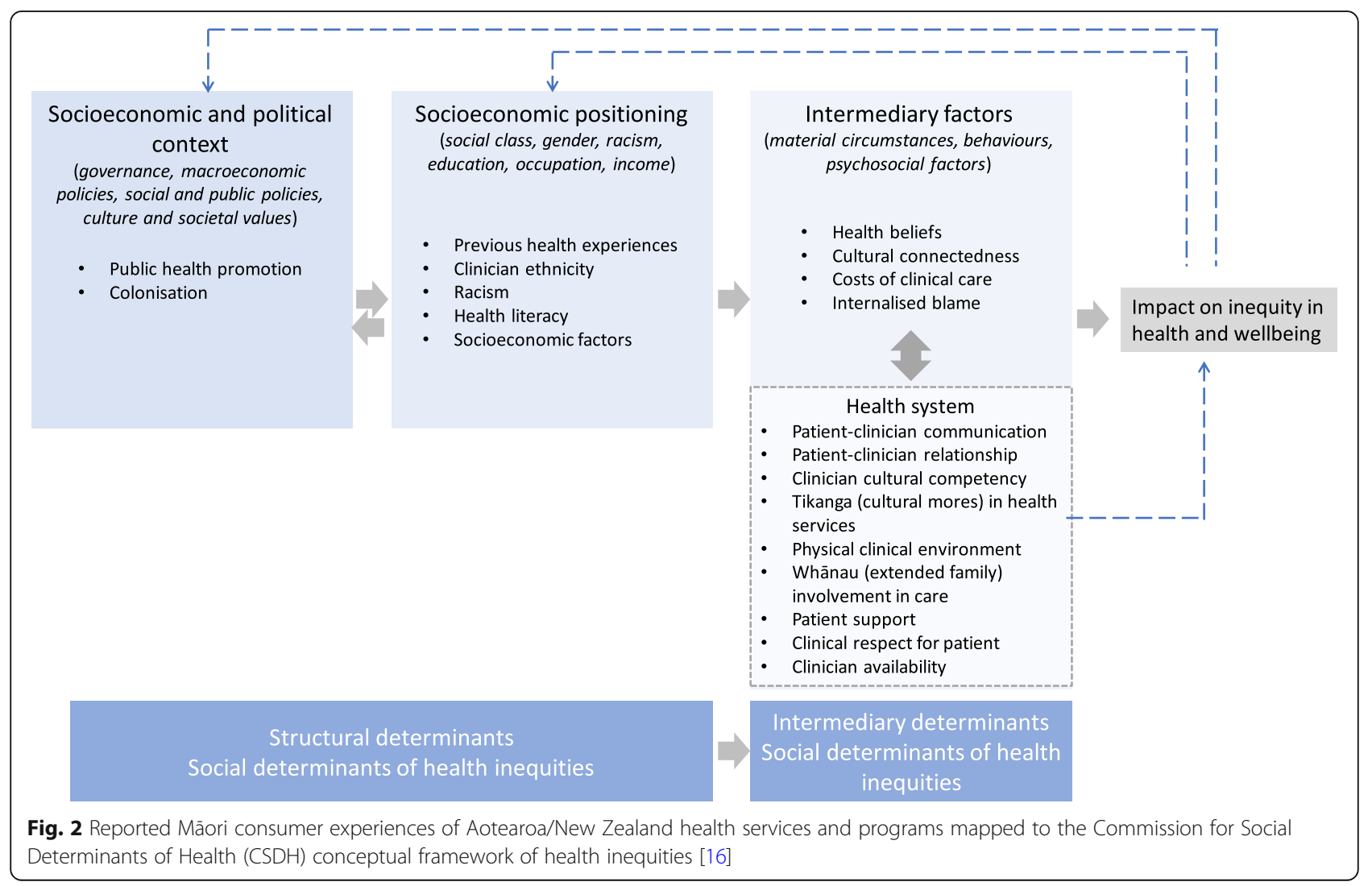




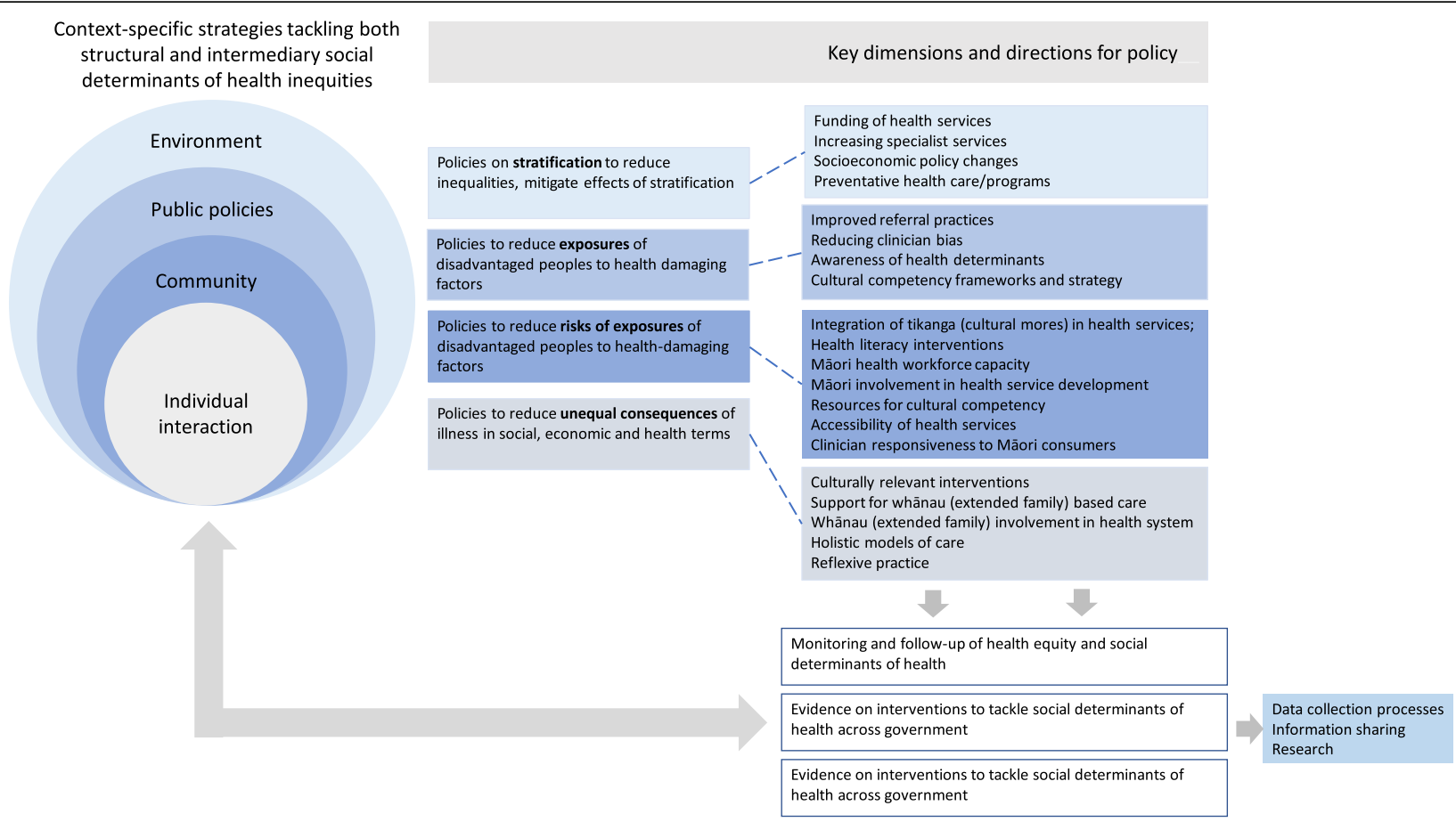

Fig. 3 Researcher recommended actions to improve Māori experiences of Aotearoa/New Zealand health services and programs mapped to the Commission for Social Determinants of Health (CSDH) conceptual framework for tackling social determinants of health inequities [16]

address Mãori health inequities informed by consumer experiences. Based on qualitative data from several health settings, direct consumer interactions with the health system and programs are important informants of the determinants of health inequity in Aotearoa New Zealand, suggesting this as a priority area for quality improvement. Aspects of care that were particularly noted were patient-clinician relationships and communication, including clinician cultural competencies. Clinical services lacked alignment with tikanga (cultural protocols and processes) and involvement of the whānau in healthcare. Other intermediary factors that contributed to health inequity included costs of clinical care to consumers and internalised blame as a consequence of racism, leading to altered (reduced) care seeking actions. Systemic factors identified from exploration of Māori consumer experiences included socioeconomic and political factors such as colonisation, public health policies, institutional racism, power imbalances between clinicians and patients and health literacy.

Mapping of the strategies that researchers recommended to improve Māori consumer experiences to the CSDH framework for tackling health inequities enabled the CDSH framework to be aligned to Māori patient, whānau and consumer perspectives of the health system. Most recommendations provided strategies to reduce the risks of exposures to health-damaging factors experienced by Māori as the direct consequences of colonisation and racism. These responses included expanded use of tikanga and culturally competent practice in health services, capacity-building to support Māori participation in the health workforce and health service development, and greater access for Māori to clinical services including health system responsiveness to Māori consumer expressed needs and expectations. Health system level strategies based on consumer perspectives included greater funding of health services, expanding specialist services for Māori and increasing preventative health care and programs. Policies to reduce the unequal consequences of illness that further drive structural inequity included the development of culturally relevant interventions and whānau (extended family) rather than individual-centred care.

The actions identified by researchers that might reduce health inequities for Maori consumers in this synthesis are concordant with evidence within other national settings including Canada and Australia [73]. These include strengthening community-governed health services, addressing power imbalances during Indigenous patient interactions with health services through trust, reciprocity, and shared decision-making, as well as avoiding a deficit model of non-adherence by Indigenous patients as an explanation for health outcomes. Similarly, in a critical interpretive synthesis of healthcare in the United Kingdom among patients with socioeconomic disadvantage, equity of access was conceptualised as a complex interplay between social context and features of the health service 
such as patient navigation and the permeability of health services to specific patient communities [74]. These findings are consistent with the present analysis that identified potential strategies to address inequities and improve services for Māori consumers informed by experiences include modifying referral structures, and increasing service and clinician accessibility and responsiveness.

These findings suggest that, in addition to the role of qualitative research to evaluate individual and community-level Māori consumer experiences within specific health settings and encounters, there is an untapped potential for qualitative and participatory research with Māori consumers to inform the development and implementation of effective policies and interventions that reduce inequities and exposure to health damaging factors at a broader macro-level [75]. Aotearoa New Zealand has a governance system with the capacity to address health inequity as required by the Treaty of Waitangi. This system includes robust quantitative data collection and reporting on social determinants of health, legislative structures that enable intersectoral action on equity, a governmental framework linked to budget, and a strong public health system. While still relatively infrequent, qualitative research that is co-designed with Māori consumers has provided examples of how participatory research actions can inform system and policy-based change to address inequity. For example, research informed by Māori consumer and clinician experiences has led to consumer-designed health service improvements including increased specialist assessment and diagnostic services in rural Tai Tokerau/Northland [12] and a culturallyacceptable intervention to support safe bed-sharing (the wahakura sleeping pod), [21] that has subsequently been adopted as policy and evaluated in a randomised controlled trial $[76,77]$.

Clinical quality improvement programs in Aotearoa New Zealand do not always improve health service experiences and outcomes for Māori and may exacerbate rather than address inequities [8-10]. Recent examples include inequities in childhood immunisations that were nearly eliminated in 2014 but have re-emerged through progressive loss of initial gains in immunisation rates among Māori children [7]. Similarly, progressive improvements in diabetes monitoring and kidney disease screening for non-Māori have not occurred for Māori patients. Knowledge of Māori consumer experiences of health care to inform understanding of structural determinants and intermediaries of health inequities may support healthcare quality improvements that sustainably reduce the unequal distribution of quality health care. Empirical analysis has demonstrated the necessity of critical reflections of power and institutional culture in the sustainable delivery of programs that are aimed to impact on health inequity $[78,79]$.
The strengths of this paper include the a priori use of a conceptual framework that considers the structural determinants of health (CSDH), a broad literature search within multiple electronic databases and two levels of coding using established methodological processes. There are also limitations of this study that need to be considered when interpreting the findings. First, we may have not identified all the relevant qualitative studies available in the literature due to challenges in retrieval of qualitative research and a lack of searching of grey literature including governmental and non-governmental reports [80]. Second, we did not include qualitative studies exploring perspectives of health providers in the review which may have captured additional methodological approaches and theoretical frameworks in existing qualitative research of Māori consumer experiences. Third, the nature of qualitative research of patient experiences is frequently focused on the individual and their immediate family, and accordingly the type of study we evaluated would be most likely to examine the direct health consequences of unequal exposure to risk factors for disease and illness.

\section{Conclusions}

Māori consumer experiences of health services and programs are an important informer of variables that impact health inequity. Strategies to tackle health inequities informed by Māori consumer experiences can be drawn from existing empirical research. Future qualitative exploration of how socioeconomic, political and public policies influence Māori consumer experiences of health services and programs could inform a broader range of structural policies to address health inequities.

\section{Supplementary information}

Supplementary information accompanies this paper at https://doi.org/10. 1186/s12939-019-1057-4.

Additional file 1. Comprehensiveness of study reporting by Consolidated Criteria for Reporting Qualitative health research.

Additional file 2. Dataset used for analysis.

\begin{abstract}
Abbreviations
COREQ: Consolidated Criteria for Reporting Qualitative Research; CSDH: Commission for Social Determinants of Health; ENTREQ: Enhancing Transparency in Reporting the Synthesis of Qualitative Research
\end{abstract}

Acknowledgements

Not applicable.

\section{Authors' contributions}

SCP conceived the study, screened the literature for eligible studies, extracted data, conducted the data coding and analysis, and drafted the manuscript. HG screened the literature for eligible studies, extracted data, conducted the data coding and analysis, and provided intellectual input into the manuscript. $\mathrm{TH}, \mathrm{CL}$, and $\mathrm{LB}$ were major contributors in writing the manuscript. SP conceived the study with SCP, conducted the data coding and analysis, and was a coequal contributor with SCP in writing the manuscript. All authors read and approved the final manuscript. 


\section{Funding}

This study received no specific funding. SCP was supported by a Rutherford Discovery Fellowship from the Royal Society of New Zealand under Grant number RDF-UOO1302.

\section{Availability of data and materials}

The dataset generated and analysed during the current study is available in the Mendeley Data repository, https://doi.org/10.17632/wgmwjscsn9.1.

\section{Ethics approval and consent to participate}

Not applicable. The research is a meta-analysis of publicly available studies.

\section{Consent for publication}

Not applicable.

\section{Competing interests}

The authors declare they have no competing interests.

\section{Author details}

'Department of Medicine, University of Otago Christchurch, 2 Riccarton Ave, Christchurch 8140, New Zealand. 'Māori and Indigenous Health Institute, University of Otago Christchurch, 45 Cambridge Terrace, Christchurch 8140, New Zealand.

Received: 8 May 2019 Accepted: 23 September 2019

Published online: 28 October 2019

\section{References}

1. Ministry of Health. Mortality and demographic data 2012. Wellington: Ministry of Health; 2015

2. Department of Corrections. Over-representation of Māori in the criminal justice system. An exploratory report. 2007. Available at http://www. corrections.govt.nz/resources/research_and_statistics/over-representation-ofmaori-in-the-criminal-justice-system.html. Accessed 16 May 2017.

3. Metcalfe S, Laking G, Arnold J. Variation in the use of medicines by ethnicity during 2006/07 in New Zealand: a preliminary analysis. N Z Med J. 2013; 126(1384):5869.

4. Robson B, Purdie G, Cormack D. Unequal impact: Māori and non-Māori Cancer statistics 1996-2001. Ministry of Health: Wellington; 2006

5. Davis P, Lay-Yee R, Dyall L, Briant R, Sporle A, Brunt D, et al. Quality of hospital care for Māori patients in New Zealand: retrospective crosssectional assessment. Lancet. 2006;367(9526):1920-5.

6. Ministry of Health. Ngā mana hauora tūtohu: Health status indicators. Wellington; 2015. Available at http://www.health.govt.nz/our-work/ populations/maori-health/tatau-kahukura-maori-health-statistics. Accessed 15 May 2017.

7. Health Quality \& Safety Commission. He matapihi ki te kounga o ngā manaakitatanga à-haoura o Aotearoa 2019. A window on the quality of Aotearoa New Zealand's health care 2019. Wellington, New Zealand. Available online at www.hqsc.govt.nz. Accessed on Sept 7, 2019. 2019.

8. Dalbeth N, Dowell T, Gerard C, Gow P, Jackson G, Shuker C, et al. Gout in Aotearoa New Zealand: the equity crisis continues in plain sight. N Z Med J. 2018;131(1485):8-12

9. Loring BJ, Ineson S, Sherwood D, Tipene-Leach D. Choosing wisely means choosing equity. N Z Med J. 2019;132(1496):6-8

10. Metcalfe S, Vallabh M, Murray P, Proffitt C, Williams G. Over and under? Ethnic inequities in community antibacterial prescribing. N Z Med J. 2019; 132(1488):65-8.

11. Bradley E, Curry L, Devers K. Qualitative data analysis for health services research: developing taxonomy, themes, and theory. Health Serv Res. 2007; 42(2):1758-72.

12. Penney L, McCreanor T, Moewaka BH. New perspectives on heart disease management in Te tai Tokerau: Māori and health practitioners talk. Auckland: Te Rōpu Whariki, Massey University; 2006.

13. Anderson I, Robson B, Connolly M, Al-Yaman F, Bjertness E, King A, et al. Indigenous and tribal peoples' health (the lancet-Lowitja Institute global collaboration): a population study. Lancet. 2016:388(10040):131-57.

14. Rushton C. Problematising the problem: a critical interpretive review of the literature pertaining to older people with cognitive impairment who fall while hospitalised. Nurs Inq. 2016;23(2):148-57.
15. Kriznik NM. "What's the problem of "health inequality" represented to be?" a post-structuralist analysis of English public health policy 1980-2011. Doctoral thesis. Faculty of Social Sciences and Health. School of Applied Social Sciences. Durham University 2015.

16. Commision on Social Determinants of Health. A conceptual framework for action on the social determinants of health. 2007. Available at http://www. who.int/social_determinants/resources/csdh_framework_action_05_07. pdf?ua=1. Accessed 12 May 2017.

17. Tong A, Flemming K, Mclnnes E, Oliver S, Craig J. Enhancing transparency in reporting the synthesis of qualitative research: ENTREQ. BMC Med Res Methodol. 2012:12:181

18. Tong A, Sainsbury P, Craig J. Consolidated criteria for reporting qualitative research (COREQ): a 32-item checklist for interviews and focus groups. Int J Qual Health Care. 2007;19(6):349-57.

19. Saldaña J. The coding manual for qualitative researchers. 2nd: Sage; 2013

20. White N, Mavoa H, Bassett S. Perceptions of health, illness and physiotherapy of Mãori identifying with Ngati Tama iwi. N Z J Physiother. 1999;27(1):5-15

21. Tipene-Leach D, Abel S, Finau SA, Park J, Lenna M. Māori infant care practices: implications for health messages, infant care services and SIDS prevention in Maori communities. Pac Health Dialog. 2000;7(1):29-37.

22. Bassett SF, Tango SM. Mãori people's experiences of being physiotherapy patients: a phenomenological study. N Z J Physiother. 2002;30(1):30-40.

23. Buetow S, Adair V, Coster G, Hight M, Gribben B, Mitchell E, et al. Health Education. 2003;103(2):88-98.

24. Cram F, Smith L, Johnstone W. Mapping the themes of Māori talk about health. N Z Med J. 2003:116(1170):1 p following U353.

25. Willams PN, Gray MA, Ka'ai TM, Moorfield JC, McPherson KM, Weinstein $P$, et al. Māori men's perceptions and experiences of health seeking for prostate health problems in New Zealand. Pac Health Dialog. 2003; 10(2):71-8.

26. Gibbs A, Dawson J, Forsyth $H$, Mullen R. Maori experience of community treatment orders in Otago, New Zealand. The Australian and New Zealand journal of Psychiatry. 2004;38(10):830-5.

27. Glover M. Analysing smoking using Te Whare Tapa Wha. N Z J Psychol. 2005;34(1):13-9

28. van der Oest $C$, Chenhall R, Hood D, Kelly PM. Talking about TB: Multicultural diversity and tuberculosis services in Waikato, New Zealand. N Z Med J. 2005:118(1216):62-73

29. Bolitho S, Huntington A. Experiences of Māori families accessing health care for their unwell children: a pilot study. Nurs Prax N Z. 2006;22(1):23-32.

30. Corbett A, Francis K, Chapman Y. The experience of whānau caring for members disabled from the effects of a cerebro-vascular accident. Contemp Nurse. 2006:22(2):255-63.

31. Buetow $S$, Janes $R$, Steed $R$, Ihimaera L, Elley CR. Why don't some women return for cervical smears? A hermeneutic phenomenological investigation. Health Care Women Int. 2007;28(9):843-52.

32. Dew K, Morgan S, Dowell A, McLeod D, Bushnell J, Collings S. 'It puts things out of your control': fear of consequences as a barrier to patient disclosure of mental health issues to general practitioners. Sociol Health IIIn. 2007; 29(7):1059-74

33. Lovell S, Kearns RA, Friesen W. Sociocultural barriers to cervical screening in South Auckland. New Zealand Soc Sci Med. 2007;65(1):138-50.

34. Fernandez C, Wilson D. Māori women's views on smoking cessation initiatives. Nurs Prax N Z. 2008;24(2):27-40.

35. Waetford $\mathrm{CH}$. The knowledge, attitudes and behaviour of young Māori women in relation to sexual health: a descriptive qualitative study. $2008 \mathrm{~A}$ thesis submitted to Auckland University of Technology in partial fulfilment of the requirements for the degree of Master of Health Science. Division of Health Care Practice Faculty of Health \& Environmental Sciences.

36. Walker $T$, Signal $L$, Russell M, Smiler $K$, Tuhiwai-Ruru R. The road we travel: Māori experience of cancer. N Z Med J. 2008;121(1279):27-35.

37. Wilson D. The significance of a culturally appropriate health service for indigenous Māori women. Contemp Nurse. 2008;28(1-2):173-88.

38. Arlidge B, Abel S, Asiasiga L, Milne SL, Crengle S, Ameratunga SN. Experiences of whānau/families when injured children are admitted to hospital: a multi-ethnic qualitative study from Aotearoa/New Zealand. Ethn Health. 2009;14(2):169-83.

39. Edwards S, McCreanor T, Ormsby M, Tuwhangai N, Tipene-Leach D. Māori men and the grief of SIDS. Death Stud. 2009;33(2):130-52. 
40. Glover M, Waldon J, Manaena-Biddle H, Holdaway M, Cunningham C. Barriers to best outcomes in breastfeeding for Māori: mothers' perceptions, Whānau perceptions, and services. J Hum Lact. 2009;25(3):307-16.

41. Glover MP, McKree A, Dyall L. Assisted human reproduction: issues for Takatapui (New Zealand indigenous non-heterosexuals). J GLBT Fam Stud. 2009;5(4):295-311.

42. Jansen P, Bacal K, Crengle S. He Ritenga Whakaaro: Māori experiences of health services. Auckland: Mauri Ora Associates 2008; 2009.

43. Wiley A. At a cultural crossroads: lessons on culture and policy from the New Zealand disability strategy. Disabil Rehabil. 2009:31(14):1205-14.

44. Handley J, Pullon S, Gifford H. Living with type 2 diabetes: 'Putting the person in the pilots' seat. Aust J Adv Nurs. 2010;27(3):12-9.

45. Laird B, Smith B, Dutu G, Mellsop G. Views and experiences of family/ whānau carers of psychiatric service users on diagnosis and classification. Int J Soc Psych. 2010:56(3):270-9.

46. McManus V, Abel S, McCreanor T, Tipene-Leach D. Narratives of deprivation: Women's life stories around Māori sudden infant death syndrone. Soc Sci Med. 2010;71:643-9.

47. Pitama S, Ahuriri-Driscoll A, Huria T, Lacey C, Robertson P. The value of te reo in primary care. J Prim Health Care. 2011;3(2):123-7.

48. Shih LC, Honey M. The impact of dialysis on rurally based Māori and their whanau/families. Nurs Prax N Z. 2011;27(2):4-15.

49. Thompson-Evans TP, Glover MP, Walker N. Cytisine's potential to be used as a traditional healing method to help indigenous people stop smoking: a qualitative study with Māori. Nicotine Tob Res. 2011;13(5):353-60.

50. Bassett-Clarke D, Krass I, Bajorek B. Ethnic differences of medicines-taking in older adults: a cross cultural study in New Zealand. Int J Pharm Pract. 2012;20(2):90-8

51. Evans D. Whakapapa, genealogy and genetics. Bioethics. 2012;26(4):182-90.

52. Glover M, Kira A. Pregnant Māori smokers' perception of cessation support and how it can be more helpful. J Smok Cessat. 2012;7(2):65-71.

53. Gray L, MacDonald C, Mackie B, Paton D, Johnston D, Baker MG Community responses to communication campaigns for influenza a $(\mathrm{H} 1 \mathrm{~N} 1)$ : a focus group study. BMC Public Health. 2012;12:205.

54. Sheridan NF, Kenealy TW, Kidd JD, Schmidt-Busby JI, Hand JE, Raphael DL, et al. Patients' engagement in primary care: powerlessness and compounding jeopardy. A qualitative study. Health Expect. 2012;18(1):32-43.

55. Wilson D, Barton P. Indigenous hospital experiences: a New Zealand case study. J Clin Nurs. 2012;21:2316-26.

56. Elder $\mathrm{H}$. Indigenous theory building for Māori children and adolescents with traumatic brain injury and their extended family. Brain Impairment. 2013; 14(3):406-14.

57. Frey R, Gott M, Raphael D, Black S, Teleo-Hope L, Lee H, et al. 'Where do I go from here'? A cultural perspective on challenges to the use of hospice services. Health Soc Care Community. 2013;21(5):519-29.

58. Johnson D, Hodgetts D, Nikora LW. A humanistic approach to addressing the needs of Mãori homeless people with mental health concerns. J Humanist Psychol. 2013;53(1):94-113.

59. Lee R, North N. Barriers to Māori sole mothers' primary health care access. J Prim Health Care. 2013;5(4):315-21.

60. Slater T, Matheson A, Davies C, Tavite H, Ruhe T, Holdaway M, et al. 'It's whānaungatanga and all that kind of stuff': Māori cancer patients' experiences of health services. J Prim Health Care. 2013;5(4):308-14.

61. Te Karu L, Bryant L, Elley CR. Māori experiences and perceptions of gout and its treatment: a kaupapa Māori qualitative study. J Prim Health Care. 2013;5(3):214-22.

62. Angelo J, Wilson L. Exploring occupation roles of hospice family caregivers from Māori, Chinese and Tongan ethnic backgrounds living in New Zealand. Occup Ther Int. 2014;21(2):81-90.

63. Bakker J, O'Keeffe K, Neill A, Campbell A. Continuous positive airway pressure treatment for obstructive sleep apnoea: Māori, Pacific and New Zealand European experiences. J Prim Health Care. 2014;6(3):221-8.

64. Johnston Taylor E, Simmonds S, Earp R, Dip PT. Māori perspectives on hospice care. Divers Equal Health Care. 2014;11(1):61-70.

65. Makowharemahihi C, Lawton BA, Cram F, Ngata T, Brown S, Robson B. Initiation of maternity care for young Māori women under 20 years of age. N Z Med J. 2014;127(1393):52-61.

66. McLellan K, McCann C, Worrall L, Harwood M. Mãori experiences of aphasia therapy: "but I'm from Hauiti and we've got shags". Int J Speech Lang Pathol. 2014;16(5):529-40.

67. The Centre for Health Activity and Rehabilitation Research, School of Physiotherapy University of Otago. Haua Mana Māori: Living unique and enriched lives. A report for the Health Research Council and the Ministry of Health. 2014.

68. Abel S, Stockdale-Frost A, Rolls R, Tipene-Leach D. The wahakura: a qualitative study of the flax bassinet as a sleep location for New Zealand Maori infants. N Z Med J. 2015;128(1413):12-9.

69. Slater T, Matheson A, Ellison-Loschmann L, Davies C, Earp R, Gellatly K, et al. Exploring Māori cancer patients', their families', community and hospice views of hospice care. Int J Palliat Nurs. 2015;21(9):439-45.

70. Warbrick I, Wilson D, Boulton A. Provider, father, and bro - sedentary Māori men and their thoughts on physical activity. Int J Equity Health. 2016;15(1):22.

71. Tapera R, Harwood M, Anderson A. A qualitative Kaupapa Māori approach to understanding infant and young child feeding practices of Māori and Pacific grandparents in Auckland, New Zealand. Public Health Nutr. 2017; 20(6):1090-8.

72. Walker R, Walker S, Morton R, Tong A, Howard K, Palmer S. Māori patients' experiences and perspectives of chronic kidney disease: a New Zealand qualitative interview study. BMJ Open. 2017;7(1):e013829.

73. Peiris $D$, Brown A, Cass $A$. Addressing inequities in access to quality health care for indigenous people. CMAJ. 2008;179(10):985-6.

74. Dixon-Woods M, Cavers D, Agarwal S, Annandale E, Arthur A, Harvey J, et al. Conducting a critical interpretive synthesis of the literature on access to healthcare by vulnerable groups. BMC Med Res Methodol. 2006:6:35.

75. Marmot M, Allen J, Bell R, Bloomer E, Goldblatt P. WHO European review of social determinants of health and the health divide. Lancet. 2012;380(9846): 1011-29.

76. Whanganui District Health Board. Wahakura/Pepi-Pods. Available at https:// wdhb.org.nz/content/page/wahakura-pepi-pods/m/0/pre/3555/. Accessed 5 Feb 2019

77. Baddock S, Tipene-Leach D, Williams S, Tangiora A, Jones R, losua E, et al. Wahakura versus bassinet for safe infant sleep: a randomized trial. Pediatrics. 2017;139(2):e20160162.

78. Pauly B, Martin W, Perkin K, van Roode T, Kwan A, Patterson T, et al. Critical considerations for the practical utility of health equity tools: a concept mapping study. Int J Equity Health. 2018;17:48

79. Raphael D. Understanding the promotion of health equity at the local level requires far more than quantitative analysis of yes-no survey data. Int J Health Policy Manag. 2018:7(10):964-7.

80. Booth A. Searching for qualitative research for inclusion in systematic reviews: a structured methological review. Syst Rev. 2016:5:74.

\section{Publisher's Note}

Springer Nature remains neutral with regard to jurisdictional claims in published maps and institutional affiliations.

Ready to submit your research? Choose BMC and benefit from:

- fast, convenient online submission

- thorough peer review by experienced researchers in your field

- rapid publication on acceptance

- support for research data, including large and complex data types

- gold Open Access which fosters wider collaboration and increased citations

- maximum visibility for your research: over $100 \mathrm{M}$ website views per year

At BMC, research is always in progress.

Learn more biomedcentral.com/submission 